\title{
"PERDA AO RUBRO" DAS ANÁLISES SUMÁRIAS DE TERRA
}

\section{J. E. de Paiva Netto}

A finalidade dêste trabalho é trazer alguns esclarecimentos ao significado do valor "perda ao rubro", que aparece nos resultados das análises sumárias de terras (solos) efetuadas pela Secção de Tecnologia Agrícola, em amostras enviadas, pelos interessados, ao Instituto Agronômico, visando, geralmente, a conselhos sôbre adubação.

Parece haver uma certa tendência em interpretar êste valor como sendo devido, em sua maior parte, à matéria orgânica contida no solo. Entretanto, podemos asseverar que em $90 \%$ dos casos, a perda ao rubro é mais diretamente proporcional à porcentagem de argila do solo, devido à água que esta retém muito fortemente.

A umidade higroscópica (outro índice que figura nas análises sumárias) então já não indica a porção de água retida por êsse solo ? Sim, ela indica a áqua retida pelo solo, mas que é expulsa quando êste é aquecido à temperatura de $110^{\circ} \mathrm{C}$.

Devemos entender, portanto, que existem pelo menos dois tipos de água: uma água que se retira aquecendo o solo até a temperatura de $110^{\circ} \mathrm{C}$. e outra que se perde quando o solo é aquecido a temperaturas mais elevadas. A água pode estar física ou quimicamente ligada aos constituintes do solo: tanto num caso como noutro, para ser retirada, necessita as mais diversas quantidades de energia. E, teòricamente, podemos admitir que para expulsar as últimas porções de água ligadas, química ou fìsicamente a uma partícula ou micela de solo, são necessárias consideráveis quantidades de energia. Sendo assim, vemos que o valor - umidade higroscópica - das análises de terra não constitue senão uma parte (às vêzes, bem pequena) de água contida no solo. A umidade 
higroscópica é a água perdida até a temperatura de $110^{\circ} \mathrm{C}$, calculada em porcentagem da substância sêca do ar.

Vejamos agora, porque é mais razoável admitir que a "perda ao rubro", em 90\% dos casos, seja proporcional ao conteúdo de argila da amostra de terra.

Pela análise mecânica de uma amostra de solo, podemos determinar, porcentualmente, as quantidades de diversos tamanhos de partículas alí existentes. Foram estabelecidas por vários autores, entre êles, Schoene (1), Kopechy (1), Atterberg (1), etc., tabelas para julgamento de valores encontrados. Nós usamos a escala sugerida por êste último, denominada por isso "escala de Atterberg", por a acharmos mais prática, e que é a seguinte :

A "terra fina" compõe-se de partículas com menos de $2 \mathrm{~mm}$ de diâmetro, assim subdivididas : a porção constituída de partículas com $2 \mathrm{~mm}$ a $0,2 \mathrm{~mm}$ de diâmetro denomina-se - areia grossa; de 0,2 $\mathrm{mm}$ a $0,02 \mathrm{~mm}$ - areia fina; de $0,02 \mathrm{~mm}$ a $0,002 \mathrm{~mm}$ - "silt" ou limo; menos de 0,002 mm - argila.

Podemos agora entender mais fàcilmente o que dịssemos sôbre a relação existente entre "perda ao rubro" e porcentagem de argila de solo.

Não nos vamos ocupar com as frações cujas partículas têm diâmetros maiores que $0,002 \mathrm{~mm}$, por terem elas, relativamente, pouca importância na interpretação do valor "perda ao rubro" que é o nosso problema. Assim ○ fazemos, porquanto, estas frações de partículas com diâmetros superiores a 0,002 $\mathrm{mm}$ são, na sua maioria, compostas de sílica (areia) cuja capacidade de reter água é muito pequena.

Passamos agora a tratar da fração que nos interessa: $\boldsymbol{a}$ argila. A composição da "argila", proveniente dos diversos tipos de solos do Estado, é muito variável. Porém, sem errarmos muito, podemos dizer que tal acontece apenas em $10 \%$ dos casos, porquanto, nos outros $90 \%$ a fração argila não varia muito de composição. De um modo geral os constituintes da fração argila dos solos do Estado são os seguintes :

1. Kaolinita - argila para porcelana, muitíssimo freqùente;

2. Montmorrilonita - argila de grande importância na alimentação das plantas e nas adubações, porém relativamente rara ; 
3. Haloisita - de propriedades semelhantes às da kaolinita, mas pouco comum;

4. Nontronita - argila bastante rara nos nossos solos;

5. Ilita, também chamada argila de mica ou argila $\mathbf{X}$ - argila pouco comum, encontrada principalmente em alúvios provenientes de restos de micasxistos, filitos, etc. ;

6. Badeleita - argila muito raramente encontrada;

7. Sílica mais ou menos hidratada - bastante comum, ocorrendo em pequena quantidade, exceto nos solos provenientes da formação geológica denominada corumbatal, dos quais é quase o único constituinte ;

8. Oxidohidratos de alumínio - freqùentes nos solos provenientes de certas formações geológicas; é um dos mais importantes constituintes da terra roxa da formação Botucatú ;

9. Oxidohidratos de ferro - aparecem também em algumas formações geológicas em grandes quantidades, sendo ainda exemplo a nossa terra roxa, da formação geológica Botucatú ;

10. Sais minerais solúveis - são também constituintes da fração argila, contudo, aparecem, geralmente, em pequena quantidade;

11. Matéria orgânica - também faz parte da fração argila, e, infelizmente, em $90 \%$ dos casos, ocorre uma pequeníssima quantidade.

Foram, assim, muito resumidamente descritos os principais constituintes da fração argila dos solos do Estado de São Paulo, a qual já foi estudada pela Secção de Solos do Instituto Agronômico, por métodos os mais precisos e modernos. Entre estes, pela sua rapidez, se destaca - método radiogramétrico, sendo que, atualmente, existem em nossos arquivos, mais de 500 radiogramas (ou Roentgenografias) da fração argila dos solos do Estado.

Apoiando-nos, principalmente, nos dados assim obtidos, procuramos achar melhor interpretação para o valor "perda ao rubro".

Consideramos no presente trabalho, os principais constituintes da fração argila que, como vimos, ocorrem em $90 \%$ dos solos do Estado.

Pela análise radioscópica sabemos que o constituinte mais comum e que entra em maior porção na fração argila, é a kaolinita ; tratando-se de terra roxa, precisamos também levar em consideração os 
óxidos-hidratados de ferro e alumínio. $\AA$ ambos cabe importante papel com relação à perda ao rubro.

Vejamos o que acontece à kaolinita quando ela é submetida a várias temperaturas. Tomemos a kaolinita pura, tipo padrão, conhecida pelo nome de kaolinita de Zettlitz. Levada a uma estufa, à temperatura de $110^{\circ} \mathrm{C}$, vamos notar uma perda de pêso de mais ou menos $0,8 \%$, conforme o estado higrométrico do ar. Essa perda porcentual de pêso, chama-se umidade higroscópica.

Agora, se levarmos a amostra de kaolinita que saiu da estufa, a $110^{\circ}$ C, para uma mufla (espécie de forno) com a temperatura de 1000 a $1200^{\circ} \mathrm{C}$, vamos observar, novamente, uma perda de pêso, muitas vêzes maior que a primeira. Esta perda pode atingir até $13,5 \%$ e é o que nas análises comuns de terra recebe o nome de perda ao rubro. A deshidratação da kaolinita de Zettlitz foi estudada detalhadamente por Klever e Kordes (2), figura 1.

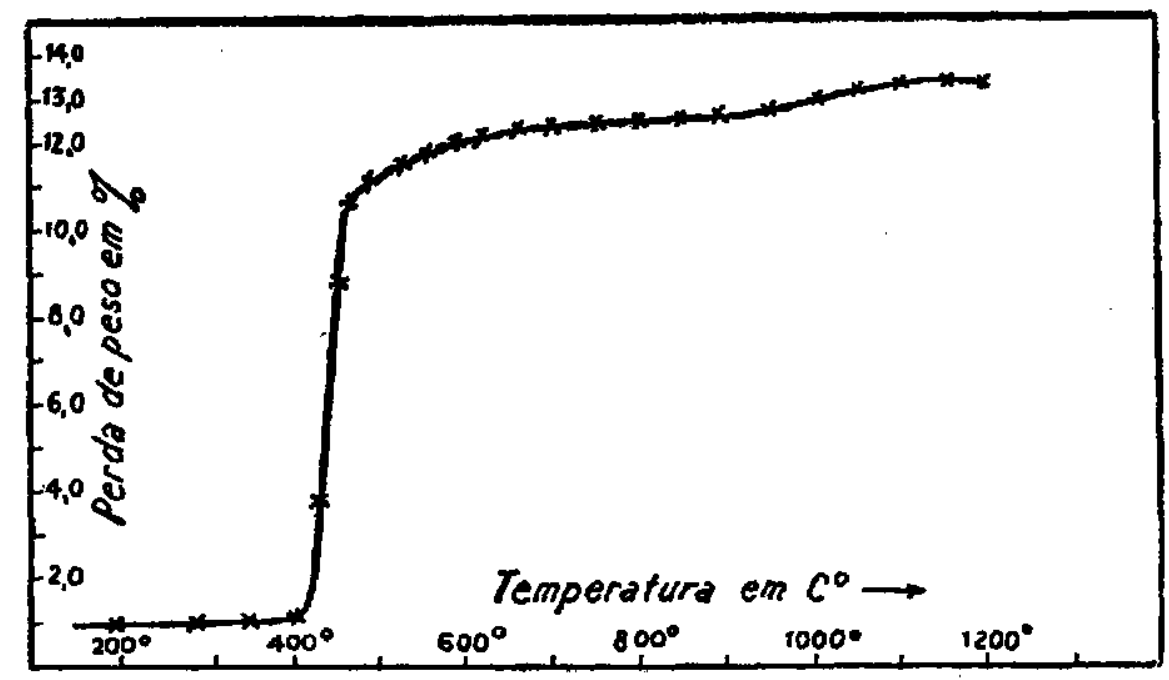

Figura I. (De Klever e Korden) (2).

$\mathrm{Na}$ figura 1 vemos que uma argila contendo $0 \%$ de matéria orgânica, como a kaolinita de Zettlitz, pode dar até $13,5 \%$ de "perda ao rubro".

Êste valor ainda será maior se a fração argila for composta de kaolin + hidróxidos de ferro e alumínio, conforme veremos adiante.

Procurando estudar o assunto no laboratório, com relação às nossas terras roxas, massapés e salmoirãa, preparamos misturas sintéticas de kaolinita com hidróxidos de ferro e alumínio, determinando a sua umidade higroscópica e perda ao rubro. 
A kaolinita usada em nossas experiências é proveniente de nosso Estado. É inteiramente idêntica à kaolinita de Zettlitz. Está registrada em nossos arquivos como Brasil II.

Damos a seguir as proporções das misturas efetuadas, bem como os resultados dos valores - umidade higroscópica e perda ao rubro.

TABELA I

1.a Série: Kaolinita + Hidróxido de alumínio

\begin{tabular}{c|c|c|c}
\hline Kaolinita & $\begin{array}{c}+ \text { hidróxido } \\
\text { de } \\
\text { alumínio }\end{array}$ & $\begin{array}{c}\% \\
\text { umidade } \\
\text { higrosc6pica }\end{array}$ & $\begin{array}{c}\% \\
\text { perda ao } \\
\text { rubro }\end{array}$ \\
\hline 100 & 0 & 0,63 & 13,70 \\
98 & 2 & 0,63 & 13,70 \\
95 & 5 & 0,70 & 14,00 \\
90 & 10 & 0,80 & 14,40 \\
80 & 20 & 1,20 & 16,20 \\
60 & 40 & 2,10 & 19,70 \\
0 & 100 & 9,30 & 26,30 \\
\hline
\end{tabular}

TABELAA II

2." Série: Kaolinita + hidróxido de ferro

\begin{tabular}{c|c|c|c}
\hline$\quad$ Kaolinita & $\begin{array}{c}+ \text { hidróxido } \\
\text { de } \\
\text { ferro }\end{array}$ & $\begin{array}{c}\% \\
\text { umidade } \\
\text { higroscópica }\end{array}$ & $\begin{array}{c}\% \\
\text { perda ao } \\
\text { rubro }\end{array}$ \\
\hline$\quad \therefore \quad$ & 2 & 0,60 & 13,90 \\
$\therefore \quad 95$ & 5 & 0,70 & 13,70 \\
90 & 10 & 1,10 & 13,70 \\
80 & 20 & 2,80 & 13,40 \\
60 & 40 & 4,90 & 12,70 \\
0 & 100 & 12,50 & 11,10 \\
\hline
\end{tabular}




\section{TABELA III}

3. Série : Kaolinita + Hidróxido de ferro + Hidróxido de alumínio

\begin{tabular}{c|c|c|c|c}
\hline Kaolinita & $\begin{array}{c}+ \text { hidróxido } \\
\text { de } \\
\text { ferro }\end{array}$ & $\begin{array}{c}+ \text { hidróxido } \\
\text { de } \\
\text { alumínio }\end{array}$ & $\begin{array}{c}\% \\
\text { umidade } \\
\text { higroscópica }\end{array}$ & $\begin{array}{c}\% \\
\text { verda ao } \\
\text { rubro }\end{array}$ \\
\hline 96 & 2 & 2 & 0,60 & 13,90 \\
90 & 5 & 5 & 1,00 & 14,50 \\
80 & 10 & 10 & 1,90 & 19,20 \\
60 & 20 & 20 & 7,40 & 17,10 \\
0 & 50 & 50 & 12,40 & 17,00 \\
\hline
\end{tabular}

TABELA IV

4." Série : Igual à terceira, porém com quantidades diferentes de hidróxidos.

\begin{tabular}{c|c|c|c|c}
\hline Kaolinita & $\begin{array}{c}+ \text { hidróxido } \\
\text { de } \\
\text { alumínio }\end{array}$ & $\begin{array}{c}+ \text { hidróxido } \\
\text { de } \\
\text { ferro }\end{array}$ & $\begin{array}{c}\% \\
\text { umidade } \\
\text { higroscópica }\end{array}$ & $\begin{array}{c}\% \\
\text { perda ao } \\
\text { rubro }\end{array}$ \\
\hline 70 & 10 & 20 & 3,40 & 15,10 \\
70 & 20 & 10 & 1,60 & 17,90 \\
50 & 40 & 10 & 3,20 & 19,70 \\
50 & 10 & 40 & 7,80 & 13,80 \\
\hline
\end{tabular}

Os dados destas experiências (Tabelas I-IV) demonstram claramente que podem aparecer elevados valores para "perda ao rubro" sem que haja matéria orgânica na substância pesquisada.

Ao interpretarmos os resultados das análises sumárias de terras, especialmente nos casos das terras-roxas, as quais geralmente mostram valores de "perda ao rubro" extraordinàriamente elevados, devemos ter presente êste fato. Assim, uma terra-roxa com $12 \%$ de "perda ao rubro" não indica que contenha $12 \%$ de matéria orgânica. Esta não atingiria $0,5 \%$; os restantes $11,5 \%$ se referem à água retida pela argila do solo, a qual foi libertada pelo aquecimento a uma temperatura superior a $110^{\circ} \mathrm{C}$.

Um outro caso interessante foi por nós observado em um perfil de solo tomado na zona de Ribeirão.Preto. 
As primeiras amostras tiradas a diferentes profundidades forneceramnos os seguintes dados:

\section{TABELA V}

\begin{tabular}{c|c|c|c}
\hline $\begin{array}{c}\text { Profundidade } \\
\mathrm{cm}\end{array}$ & $\begin{array}{c}\text { umidade } \\
\text { higroscópica }\end{array}$ & $\begin{array}{c}\text { perda ao } \\
\text { rubro }\end{array}$ & $\begin{array}{c}\text { matéria } \\
\text { orgânica }\end{array}$ \\
\hline 0 a 40 & 4,30 & 11,90 & 0,90 \\
40 a 80 & 3,50 & 11,00 & 0,20 \\
80 a 150 & 3,30 & 11,20 & Pràticamente nula \\
\hline
\end{tabular}

Observamos, pelos dados obtidos, Tabela V, que a perda ao rubro, nos três horizontes mencionados, é aproximadamente constante, ao passo que a quantidade de matéria orgânica cai de $0,9 \mathrm{a}$, pràticamente, $0 \%$. O terceiro horizonte pode ser comparado com as argilas sintéticas (ver tabelas I-IV), nas quais tôda a "perda ao rubro" é devida à água.

Vejamos um outro exemplo: trata-se de um perfil de solo massapé proveniente da formação arqueana. Dêsse perfil tiraram-se 3 amostras - a primeira de 0 a $40 \mathrm{~cm}$; a segunda de 40 a $80 \mathrm{~cm}$; a terceira de 80 a $150 \mathrm{~cm}$ de profundidade (ver tabela VI).

\section{TABELA VI}

\begin{tabular}{c|c|c|c}
\hline $\begin{array}{c}\text { Profundidade } \\
\text { cm }\end{array}$ & $\begin{array}{c}\text { umidade } \\
\text { higroscópica }\end{array}$ & $\begin{array}{c}\text { perda ao } \\
\text { rubro }\end{array}$ & $\begin{array}{c}\text { matéria } \\
\text { orgânica }\end{array}$ \\
\hline 0 a 40 & 1,80 & 10,50 & 1,30 \\
40 a 80 & 1,60 & 9,20 & 0,30 \\
80 a 150 & 1,60 & 9,60 & Pràticamente nula \\
\hline
\end{tabular}

Aplicam-se a êste outro tipo de solo as mesmas considerações do caso anterior.

Finalmente, consideremos o exemplo de um perfil da formação geológica Corumbatá, cuja argila tem composição muito diferente das anteriores. Como já dissemos, a fração argila dêsse solo, compõe-se quase exclusivamente de sílica mais ou menos hidratada.

A amostra dêsse perfil foi tirada de 80 a $150 \mathrm{~cm}$ de profundidade; os resultados obtidos foram os seguintes: 


$\begin{array}{ll}\text { água higroscópica : } & 3,60 \\ \text { perda ao rubro : } & 17,60 \\ \text { matéria orgânica : } & \text { Pràticamente nula. }\end{array}$

A-pesar-de não haver aí matéria orgânica, a perda ao rubro foi muito elevada, e deve ser atribuída, forçosamente, à água.

Ficam assim exemplificados os casos mais importantes e mais freqùentemente encontrados no nosso Estado. Concluímos, pois, que, no geral, a expressão perda ao rubro não significa matéria orgânica. Também podemos asseverar que é bem difícil, com êsse valor, calcular, mesmo aproximadamente, a porcentagem de matéria orgânica de um solo.

A determinação mais ou menos exata de matéria orgânica só pode ser feita por um processo químico direto.

\section{I T E R A T U R A C I TA DA}

1. Branch, E. Em Handbuch der Bodenlehre. vol. 6, págs. 1-66. Julius Springer, Berlin, 1930.

2. Klever, E. e E. Kordes. Kalorimetrische Untersuchungen an entwaesserten Kaolin. Veröffenthichungen aus dem Kaiser Wilhelm Institüt für Silikatforschung in Berlin-Dahlen. 3:17-22. fig. 1-2. tab. 1. 1930. 